\title{
PRDX2 protects hepatocellular carcinoma SMMC-7721 cells from oxidative stress
}

\author{
SILEI ZHOU ${ }^{1,2^{*}}$, QUANLI HAN ${ }^{3 *}$, RU WANG ${ }^{4 *},{\text { XIN } \text { LI }^{2} \text {, QINGYANG WANG }}^{2}$, \\ HUIZHONG WANG $^{4}$, JING WANG $^{5}$ and YUANFANG MA ${ }^{1}$ \\ ${ }^{1}$ Key Laboratory of Cellular and Molecular Immunology, Henan University, Kaifeng, Henan 475001; \\ ${ }^{2}$ Department of Molecular Immunology, Institute of Basic Medical Sciences, Beijing 100850; \\ ${ }^{3}$ Department of Medical Oncology 2, Chinese PLA General Hospital \& Chinese PLA Medical Academy, Beijing 100853; \\ ${ }^{4}$ Clinical Laboratory, 305 Hospital of PLA, Beijing 100017; ${ }^{5}$ Department of Radiation Oncology, \\ Chinese PLA General Hospital \& Chinese PLA Medical Academy, Beijing 100853, P.R. China
}

Received April 4, 2015; Accepted June 2, 2016

DOI: $10.3892 /$ ol.2016.4899

\begin{abstract}
Peroxiredoxin2 (PRDX2) is a member of the peroxiredoxin family of antioxidant enzymes. A number of previous studies have indicated that PRDX2 may serve a cell type-dependent role in tumorigenesis. Recently, PRDX2 has been identified to be the new target of miR-122a, which has been demonstrated to be frequently downregulated in hepatocellular carcinoma (HCC). Thus, PRDX2 may have a pro-tumorigenic role in HCC. Because the role of PRDX2 in HCC has not yet been reported, it is of interest to explore how PRDX2 may affect reactive oxygen species (ROS)-mediated cell death in HCC cells. The present study analyzed the effects of PRDX2 knockdown or overexpression on hydrogen peroxide $\left(\mathrm{H}_{2} \mathrm{O}_{2}\right)$-induced cell death in $\mathrm{HCC}$ SMMC-7721 cells. Tumor necrosis factor- $\alpha$ (TNF- $\alpha$ )-induced cell death upon PRDX2 knockdown or overexpression was also examined in SMMC-7721 cells. It was found that PRDX2 knockdown augmented $\mathrm{H}_{2} \mathrm{O}_{2}$-induced cell death in SMMC-7721 cells, whereas PRDX2 overexpression exhibited opposite effects. By contrast, PRDX 2 knockdown enhanced TNF- $\alpha$-induced apoptosis, whereas PRDX2 overexpression reduced it, even though both treatments showed little effects on TNF- $\alpha$-induced necrosis in SMMC-7721 cells. Further exploration confirmed PRDX2 knockdown led to enhanced ROS generation in response to
\end{abstract}

Correspondence to: Professor Yuanfang Ma, Key Laboratory of Cellular and Molecular Immunology, Henan University, 300 Jin-Ming Da dao, Kaifeng, Henan 475001, P.R. China

E-mail: mayf@henu.edu.cn

Dr Jing Wang, Department of Radiation Oncology, Chinese PLA General Hospital \& Chinese PLA Medical Academy, 28 Fuxing Road, Haidian, Beijing 100853, P.R. China

E-mail: wanjingmd@hotmail.com

*Contributed equally

Key words: peroxiredoxin 2, oxidative stress, cell death, apoptosis, hepatocellular carcinoma
$\mathrm{H}_{2} \mathrm{O}_{2}$. Taken together, the present study supports that PRDX2 serves a pro-tumorigenic role in HCC through, at least partially, limiting ROS-mediated apoptosis under oxidative stress.

\section{Introduction}

Hepatocellular carcinoma (HCC) is the third most common cause of cancer-associated mortality worldwide, particularly in Africa and Asia (1). Despite extensive studies, the key molecules that control the development and progression of $\mathrm{HCC}$ remain unclear.

Members of the peroxiredoxWin (PRDX) family reduce hydrogen peroxide $\left(\mathrm{H}_{2} \mathrm{O}_{2}\right)$ and alkyl hydroperoxides. PRDX2 is a member of the peroxiredoxin family of antioxidant enzymes. Similar to PRDXs, PRDX2 has been demonstrated to form disulfide-linked homodimers during its catalytic cycle (2). The expression of PRDX2 is unregulated in breast cancer, cervical cancer and colorectal cancer (3-6). By contrast, silencing of PRDX2 occurs in acute myeloid leukemia and malignant melanomas $(7,8)$. Therefore, PRDX2 may serve a cell type-dependent role in tumorigenesis.

The pro-tumorigenic role of PRDX2 may be attributed to, at least partially, protecting cells from oxidative stress (3-6). Under oxidative stress, reactive oxygen species (ROS) also contribute to tumor necrosis factor- $\alpha$ (TNF- $\alpha$ )-induced cell death (9). However, the role of PRDX2 in TNF- $\alpha$-induced cell death has not yet been established. Recently, PRDX2 has been identified to be the novel target of miR-122a, which has been demonstrated to be frequently downregulated in HCC (10). Thus, PRDX2 may serve a pro-tumorigenic role in HCC. Because the role of PRDX2 in HCC has not been reported, it is of interest to explore how PRDX2 may affect ROS-mediated cell death in HCC cells. The present study aims to examine the role of PRDX2 in $\mathrm{H}_{2} \mathrm{O}_{2}$ - or TNF- $\alpha$-induced cell death in HCC SMMC-7721 cells.

\section{Materials and methods}

Cell culture and transfection. Cells were purchased from the Shanghai Institutes for Biological Sciences (Shanghai, 
China) and were cultured in Dulbecco's modified Eagle's medium supplemented with $10 \%$ fetal bovine serum (Hyclone), $100 \mathrm{U} / \mathrm{ml}$ penicillin, and $100 \mu \mathrm{g} / \mathrm{ml}$ streptomycin and were maintained at $37^{\circ} \mathrm{C}$ with $5 \% \mathrm{CO}_{2}$. Transfection was performed with Lipofectamine 2000 (Invitrogen: ThermoFisher Scientific, Inc., Waltham, MA, USA) according to the manufacturer's protocol. The transfection procedure used 6-well plates, and 100 pmol siRNA or $1 \mu \mathrm{g}$ plasmid was used for each well. Cells were treated for at least $48 \mathrm{~h}$ for siRNA transfection, and $24 \mathrm{~h}$ for plasmid transfection. Small interfering RNA (siRNA) targeting PRDX2 (5'-CCAGTACACAGACGAGCAT-3') and non-targeting control (NC) siRNA were obtained from Shanghai GenePharma, Inc. (Shanghai, China). Mammalian expression vector encoding PRDX2 was generated by cloning PCR-amplified products into pEGFP-N1 (Sino Biological, Inc., Beijing, China) vector and confirmed by DNA sequencing. For PRDX2 siRNA, NC siRNA was used as a control. For pGFPPRDX2, the pEGFP-N1 empty vector was used as a control.

Immunoblotting analysis. Cells were washed twice with ice-cold PBS and were then lysed with $20 \mathrm{mM}$ Tris/ $\mathrm{HCl}$ (pH 7.6), 250 mM NaCl, 3 mM EDTA, 3 mM EGTA, 0.5\% NP40, $1 \mathrm{mM}$ DTT, $5 \mathrm{mM} \mathrm{NaF}, 2 \mathrm{mM} \mathrm{Na}_{3} \mathrm{VO}_{4}$ and $0.2 \mu \mathrm{M}$ Aprotinin. The whole cell extract was clarified at $4{ }^{\circ} \mathrm{C}$ at $12,000 \mathrm{rpm}$ for $15 \mathrm{~min}$. The amount of protein recovered was quantified with Bradford protein assay. Equal amounts of proteins were resolved by sodium dodecyl sulfate-polyacrylamide gel electrophoresis (SDS-PAGE) and then transferred to Hybond-P polyvinylidene difluoride (PVDF) membranes. Membranes were sequentially incubated with primary antibody over night at $4^{\circ} \mathrm{C}$ and horseradish peroxidase-conjugated polyclonal goat anti-rabbit or anti-mouse secondary antibodies (cat. no. ZB2301 and ZB2305, respectively; 1:5,000; Beijing Zhongshan Golden Bridge Biotechnology Co., Ltd., Beijing, China) for $1 \mathrm{~h}$ at room temperature. Bound antibody was detected using ECL chemiluminescence kit (GE Healthcare, Little Chalfont, UK) and Kodak X-ray film. Monoclonal mouse anti-human antibody against PRDX2 was purchased from Proteintech (cat. no. 60202-1-Ig, 1:1,000; Wuhan, China). Monoclonal mouse anti-human antibody against $\beta$-actin (cat. no. sc-8432; 1:5,000) was obtained from Santa Cruz Biotechnology, Inc. (Dallas, TX, USA).

Cell death assays. Cells were adjusted to a density of $2 \times 10^{5}$ cells/ml, and $0.5 \mathrm{ml}$ was added to each well of a 24 -well plate. Cells were treated with $10 \mathrm{ng} / \mathrm{ml} \mathrm{TNF-} \alpha$ and $1 \mu \mathrm{g} / \mathrm{ml}$ cycloheximide (CHX, Sigma-Aldrcih, St. Louis, MO, USA) or $300 \mu \mathrm{M} \mathrm{H}_{2} \mathrm{O}_{2}$ for $24 \mathrm{~h}$. Cells were washed with PBS twice and stained with Annexin V-PE/7-aminoactinomycin D (7AAD) or Annexin V-FITC/propidium iodide (PI) (Nanjing KeyGen Biotech, Nanjing, Jiangsu, China) for $15 \mathrm{~min}$ at room temperature in the dark. The level of cell death was determined by measuring the fluorescence of the cells with a flow cytometer (Becton-Dickinson, Franklin Lakes, NJ, USA).

ROS production assays. A LIVE Green Reactive Oxygen Species Detection Kit (Molecular Probes, Eugene, OR, USA) was used for detecting the generation of ROS. Briefly, cells were incubated in serum-free RPMI medium containing $2 \mu \mathrm{M}$ carboxy $-\mathrm{H}_{2}$ DCFDA (Molecular Probes) at $37^{\circ} \mathrm{C}$ for $30 \mathrm{~min}$.
Cells were washed with PBS and were immediately subjected to flow cytometry to analyse the intensity of green fluorescence at a $488 \mathrm{~nm}$ excitation wavelength.

Statistical analysis. Statistically significant differences between groups were identified using 2-tailed Student's $t$ test. $\mathrm{P}<0.05$ was considered to indicate a statistically significant difference. Statistical analysis was conducted using SPSS version 13.0 (SPSS, Inc., Chicago, IL, USA).

\section{Results}

Validation of anti-PRDX2 antibody and PRDX2 siRNA. To explore the role of PRDX2 in ROS-mediated cell death in HCC SMMC-7721 cells, a mammalian expression vector encoding GFP-PRDX2 was constructed and a PRDX2 siRNA was designed. SMMC-7721 cells were transfected with the mammalian expression vector encoding GFP-PRDX2 or left untreated. $24 \mathrm{~h}$ later, cell lysates were harvested and subjected to immunoblotting analysis. The data revealed that exogenous GFP-PRDX2 could be detected by an anti-PRDX2 antibody as well as by an anti-GFP antibody (Fig. 1A). Therefore, the anti-PRDX2 antibody detected PRDX2 protein successfully. SMMC-7721 cells were transfected with PRDX2 siRNA or non-targeting control siRNA. Cell lysates were harvested $72 \mathrm{~h}$ later. Immunoblotting analysis with the anti-PRDX2 antibody confirmed that PRDX2 expression was efficiently knocked down (Fig. 1B). Thus, the mammalian expression vector encoding GFP-PRDX2 and PRDX2 siRNA are useful tools to explore the role of PRDX2 in oxidative stress-mediated cell death in HCC SMMC-7721 cells.

PRDX2 knockdown augmented $\mathrm{H}_{2} \mathrm{O}_{2}$-induced cell death in SMMC-7721 cells. SMMC-7721 cells were transfected with PRDX2 siRNA or non-targeting control siRNA. A total of $48 \mathrm{~h}$ later, cells were treated with or without $300 \mu \mathrm{M} \mathrm{H}_{2} \mathrm{O}_{2}$ for $24 \mathrm{~h}$. Cell death assays with Annexin V-FITC/PI staining revealed that $\mathrm{H}_{2} \mathrm{O}_{2}$-induced total cell death (apoptosis plus necrosis, Fig. 2A) increased form $\sim 11$ to $\sim 17 \%$ upon PRDX2 knockdown (Fig. 2B; P<0.05). However, PRDX2 knockdown showed no effects on basal level of cell death (Fig. 2A and B). Taken together, these data suggest that PRDX2 antagonizes $\mathrm{H}_{2} \mathrm{O}_{2}$-induced cell death in SMMC-7721 cells.

PRDX2 overexpression inhibited $\mathrm{H}_{2} \mathrm{O}_{2}$-induced cell death in SMMC-7721 cells. SMMC-7721 cells were transfected with the mammalian expression vectors encoding GFP or GFP-PRDX2. A total of $24 \mathrm{~h}$ later, cells were treated with or without $300 \mu \mathrm{M} \mathrm{H}_{2} \mathrm{O}_{2}$ for $24 \mathrm{~h}$. Cell death assays with Annexin V-PE/7AAD staining revealed that $\mathrm{H}_{2} \mathrm{O}_{2}$-induced total cell death (Fig. 3A) in GFP+ population decreased $\sim 6 \%$ upon PRDX2 overexpression (Fig. 3B; P<0.05) despite that PRDX2 overexpression showed no effects on basal level of cell death (Fig. 3A and B). Together, these data confirm that PRDX2 antagonizes $\mathrm{H}_{2} \mathrm{O}_{2}$-induced cell death in SMMC-7721 cells.

PRDX2 knockdown augmented TNF- $\alpha$-induced apoptosis in SMMC-7721 cells. TNF- $\alpha$ usually does not induce cell death unless de novo protein synthesis is blocked (11). In this regard, protein synthesis inhibitor cloheximide $(\mathrm{CHX})$ is widely used to 
A

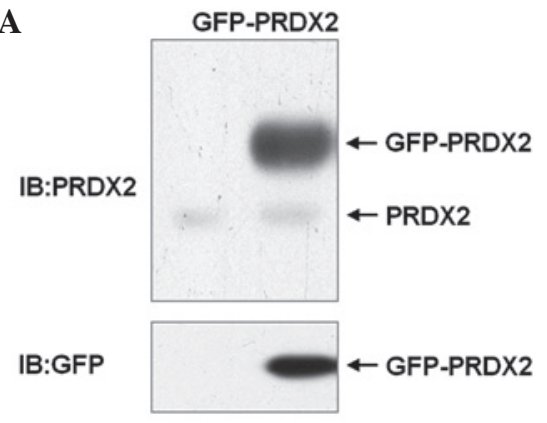

B

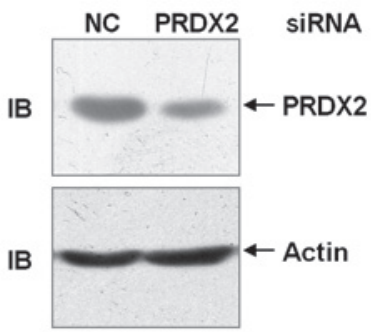

Figure 1. Validation of anti-PRDX2 antibody and PRDX2 siRNA. (A) SMMC-7721 cells were transfected with the mammalian expression vector encoding GFP-PRDX2 or left untreated; $24 \mathrm{~h}$ later, cell lysates were harvested and subjected to immunoblotting analysis with the indicated antibodies. (B) SMMC-7721 cells were transfected with PRDX2 siRNA or non-targeting control siRNA; $72 \mathrm{~h}$ later, cell lysates were harvested and subjected to immunoblotting analysis with the indicated antibodies. PRDX2, peroxiredoxin 2; siRNA, small interfering RNA.

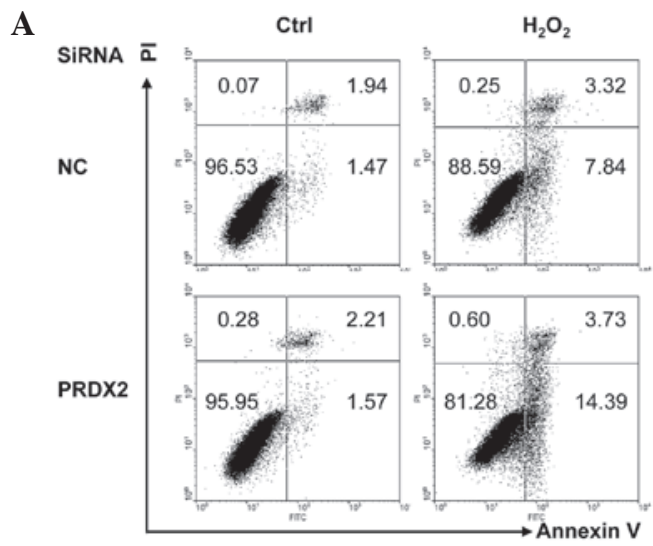

B

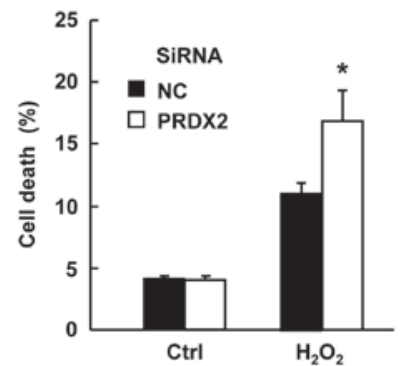

Figure 2. PRDX2 knockdown augmented $\mathrm{H}_{2} \mathrm{O}_{2}$-induced cell death in SMMC-7721 cells. SMMC-7721 cells were transfected with PRDX2 siRNA or non-targeting control siRNA; $48 \mathrm{~h}$ later, cells were treated with or without $300 \mu \mathrm{M} \mathrm{H}_{2} \mathrm{O}_{2}$ for $24 \mathrm{~h}$. Cell death assays was performed with Annexin V-FITC/PI staining. (A) Representative data. (B) Statistical data. ${ }^{*} \mathrm{P}<0.05$. PRDX2, peroxiredoxin 2; siRNA, small interfering RNA.

A

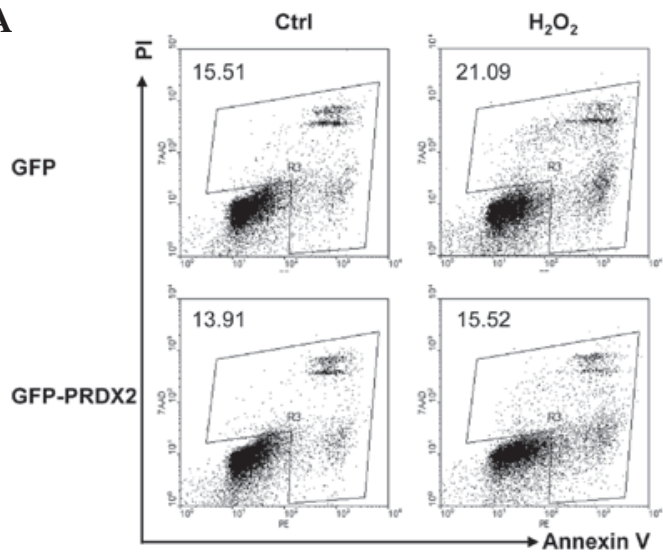

B

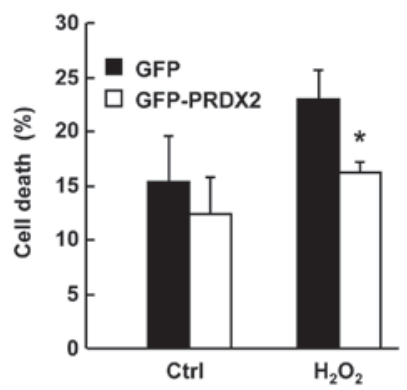

Figure 3. PRDX2 overexpression inhibited $\mathrm{H}_{2} \mathrm{O}_{2}$-induced cell death in SMMC-7721 cells. SMMC-7721 cells were transfected with the mammalian expression vectors encoding GFP or GFP-PRDX2; $24 \mathrm{~h}$ later, cells were treated with or without $300 \mu \mathrm{M} \mathrm{H}_{2} \mathrm{O}_{2}$ for $24 \mathrm{~h}$. Cell death assays was performed with Annexin V-PE/7AAD staining. GFP+ cells were gated. (A) Representative and (B) statistical data."P<0.05. PRDX2, peroxiredoxin 2.

facilitate TNF- $\alpha$-induced cell death, which includes both apoptosis and necrosis (12). SMMC-7721 cells were transfected with PRDX2 siRNA or non-targeting control siRNA. Then $48 \mathrm{~h}$ later, cells were treated with or without $10 \mathrm{ng} / \mathrm{ml} \mathrm{TNF}-\alpha$ plus $1 \mu \mathrm{g} / \mathrm{ml}$ CHX for $24 \mathrm{~h}$. Cell death assays with Annexin V-FITC/PI staining revealed that TNF- $\alpha$-induced total cell death (apoptosis plus necrosis, Fig. 4A) increased marginally upon PRDX2 knockdown. More careful examination of the data revealed the enhancement of cell death occurred only in apoptosis, namely Annexin V+PI- part. Annexin V+PI- cells increased from $\sim 9$ to $\sim 12 \%$ upon PRDX2 knockdown (Fig. 4B). However, PRDX2 knockdown showed no effects on the basal level of cell death (Fig. 4A and B). Taken together, these data suggest that PRDX2 antagonizes TNF- $\alpha$-induced apoptosis in SMMC-7721 cells. 
A SiRna

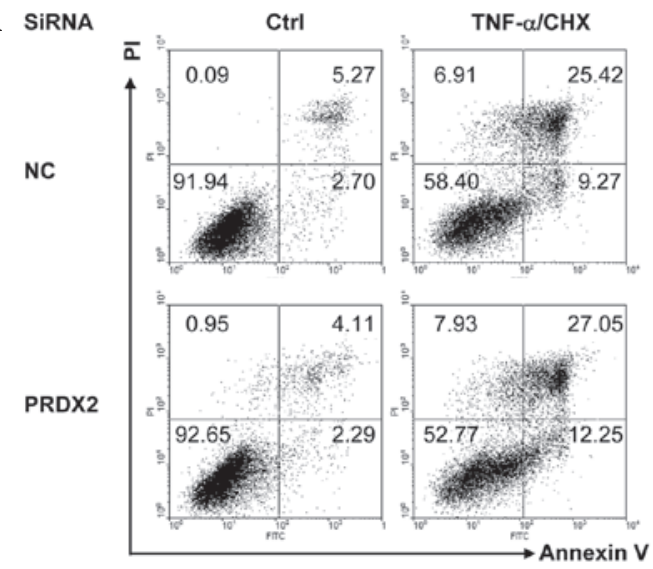

B

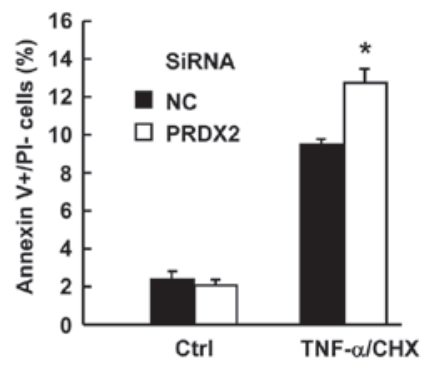

Figure 4. PRDX2 knockdown augmented TNF- $\alpha$-induced apoptosis in SMMC-7721 cells. SMMC-7721 cells were transfected with PRDX2 siRNA or non-targeting control siRNA; $48 \mathrm{~h}$ later, cells were treated with or without $10 \mathrm{ng} / \mathrm{ml} \mathrm{TNF}-\alpha$ plus $1 \mu \mathrm{g} / \mathrm{ml} \mathrm{CHX}$ for $24 \mathrm{~h}$. Cell death assays was performed with Annexin V-FITC/PI staining. (A) Representative and (B) statistical data."P<0.05. PRDX2, peroxiredoxin 2; siRNA, small interfering RNA; CHX, cycloheximide.

A

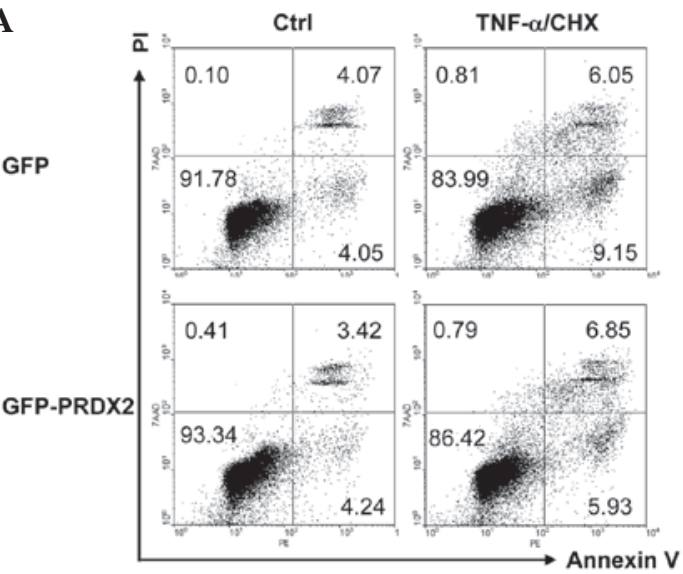

B

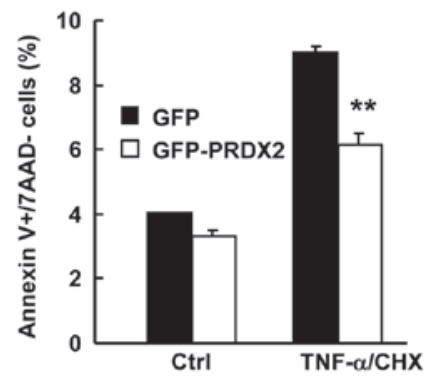

Figure 5. PRDX2 overexpression inhibited TNF- $\alpha$-induced apoptosis in SMMC-7721 cells. SMMC-7721 cells were transfected with the mammalian expression vectors encoding GFP or GFP-PRDX2. $24 \mathrm{~h}$ later, $10 \mathrm{ng} / \mathrm{ml} \mathrm{TNF-} \alpha$ plus $1 \mu \mathrm{g} / \mathrm{ml} \mathrm{CHX} \mathrm{for} 12 \mathrm{~h}$. Cell death assays was performed with Annexin V-PE/7AAD staining. GFP+ cells were gated. (A) Representative data and (B) statistical data. ${ }^{* *} \mathrm{P}<0.01$. PRDX2, peroxiredoxin 2; siRNA, small interfering RNA; CHX, cycloheximide.

PRDX2 overexpression inhibited TNF- $\alpha$-induced apoptosis in SMMC-7721 cells. It is possible that $24 \mathrm{~h}$ treatment of SMMC-7721 cell with $10 \mathrm{ng} / \mathrm{ml} \mathrm{TNF-} \alpha$ plus $1 \mu \mathrm{g} / \mathrm{ml} \mathrm{CHX}$ is too long a time to observe the effect of PRDX2 on necrosis. It may therefore be better to shorten the treatment time. SMMC-7721 cells were transfected with the mammalian expression vectors encoding GFP or GFP-PRDX2. A total of $24 \mathrm{~h}$ later, cells were treated with or without TNF- $\alpha$ plus CHX for $12 \mathrm{~h}$. Cell death assays with Annexin V-PE/7AAD staining revealed that TNF- $\alpha$-induced apoptosis (Fig. 5A) in $\mathrm{GFP}+$ population decreased $\sim 3 \%$ upon PRDX2 overexpression (Fig. 5B; P<0.01). However, PRDX2 overexpression showed no effects on TNF- $\alpha$-induced necrosis and basal level of cell death (Fig. 5A and B). Together, these data confirm that PRDX2 antagonizes TNF- $\alpha$-induced apoptosis, but not necrosis, in SMMC-7721 cells.

PRDX2 knockdown led to enhanced ROS generation in response to $\mathrm{H}_{2} \mathrm{O}_{2}$. As a member of the peroxiredoxin family of antioxidant enzymes, PRDX2 should exert its protective effects under oxidative stress by reducing ROS generation (4). In this regard, SMMC-7721 cells were transfected with PRDX2
Ctrl

$\mathrm{H}_{2} \mathrm{O}_{2}$
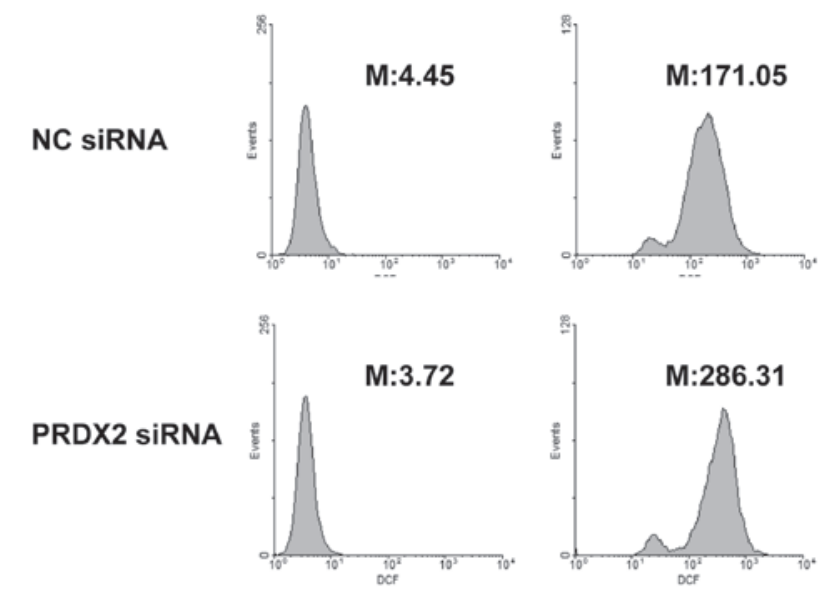

Figure 6. PRDX2 knockdown led to enhanced ROS generation in response to $\mathrm{H}_{2} \mathrm{O}_{2}$. SMMC-7721 cells were transfected with PRDX2 siRNA or non-targeting control siRNA; $72 \mathrm{~h}$ later, cells were treated with or without $300 \mu \mathrm{M}$ $\mathrm{H}_{2} \mathrm{O}_{2}$ for 30 min. ROS generation was measured by incubating cells with carboxy- $\mathrm{H}_{2}$ DCFDA simultaneously, followed by flow cytometry. M, mean fluorescence value; PRDX2, peroxiredoxin 2; siRNA, small interfering RNA ROS, reactive oxygen species. 
siRNA or non-targeting control siRNA. A total of $72 \mathrm{~h}$ later, cells were treated with or without $300 \mu \mathrm{M} \mathrm{H}_{2} \mathrm{O}_{2}$ for $30 \mathrm{~min}$. ROS generation was measured by incubating cells with carboxy- $\mathrm{H}_{2}$ DCFDA simultaneously. Flow cytometry revealed that $\mathrm{H}_{2} \mathrm{O}_{2}$ significantly induced ROS generation (Fig. 6). As expected, PRDX2 knockdown led to enhanced ROS generation in response to $\mathrm{H}_{2} \mathrm{O}_{2}$ (Fig. 6).

\section{Discussion}

The role of PRDX2 in HCC remains unknown. The present study demonstrated that PRDX2 is expressed in HCC SMMC-7721 cells and prevents ROS generation and cell death under oxidative stress. These findings imply a pro-tumorigenic role for PRDX2 in HCC.

Besides preventing $\mathrm{H}_{2} \mathrm{O}_{2}$-induced cell death, PRDX2 also serves a role in TNF- $\alpha$-induced cell death. It is known that TNF- $\alpha$ induces both apoptosis and programmed necrosis, which are mediated by distinct signaling pathways (12). The present study further supports this notion: It was demonstrated that PRDX2 only inhibits TNF- $\alpha$-induced apoptosis, but does not affect TNF- $\alpha$-induced necrosis even at early time point. Thus, ROS contributes to apoptosis pathway, but not the necrosis pathway, in response to TNF- $\alpha$.

In addition, it should be noted that the effects of PRDX2 on ROS-mediated cell death in HCC SMMC-7721 cells are weak. It is possible that other members of the peroxiredoxin family of antioxidant enzymes serve more important roles. It is also possible antioxidant enzymes of this type are not major players in cells of liver origin.

\section{References}

1. Llovet JM, Burroughs A and Bruix J: Hepatocellular carcinoma. Lancet 362: 1907-1917, 2003.
2. Moon JC, Hah YS, Kim WY, Jung BG, Jang HH, Lee JR, Kim SY, Lee YM, Jeon MG, Kim CW, et al: Oxidative stress-dependent structural and functional switching of a human 2-Cys peroxiredoxin isotype II that enhances HeLa cell resistance to $\mathrm{H} 2 \mathrm{O} 2$-induced cell death. J Biol Chem 280: 28775-28784, 2005.

3. Lu W, Fu Z, Wang H, Feng J, Wei J and Guo J: Peroxiredoxin 2 is upregulated in colorectal cancer and contributes to colorectal cancer cells' survival by protecting cells from oxidative stress. Mol Cell Biochem 387: 261-270, 2014.

4. Stresing V, Baltziskueta E, Rubio N, Blanco J, Arriba MC, Valls J, Janier M, Clézardin P, Sanz-Pamplona R, Nieva C, et al: Peroxiredoxin 2 specifically regulates the oxidative and metabolic stress response of human metastatic breast cancer cells in lungs. Oncogene 32: 724-735, 2013.

5. Noh DY, Ahn SJ, Lee RA, Kim SW, Park IA and Chae HZ: Overexpression of peroxiredoxin in human breast cancer. Anticancer Res 21: 2085-2090,2001.

6. Kim K, Yu M, Han S, Oh I, Choi YJ, Kim S, Yoon K, Jung M and Choe W: Expression of human peroxiredoxin isoforms in response to cervical carcinogenesis. Oncol Rep 21: 1391-1396, 2009.

7. Agrawal-Singh S, Isken F, Agelopoulos K, Klein HU, Thoennissen NH, Koehler G, Hascher A, Bäumer N, Berdel WE, Thiede $\mathrm{C}$, et al: Genome-wide analysis of histone $\mathrm{H} 3$ acetylation patterns in AML identifies PRDX2 as an epigenetically silenced tumor suppressor gene. Blood 119: 2346-2357, 2012.

8. Furuta J, Nobeyama Y, Umebayashi Y, Otsuka F, Kikuchi K and Ushijima T: Silencing of Peroxiredoxin 2 and aberrant methylation of $33 \mathrm{CpG}$ islands in putative promoter regions in human malignant melanomas. Cancer Res 66: 6080-6086, 2006.

9. Delhalle S, Deregowski V, Benoit V, Merville MP and Bours V: NF-kappaB-dependent MnSOD expression protects adenocarcinoma cells from TNF-alpha-induced apoptosis. Oncogene 21: 3917-3924, 2002

10. Diao S, Zhang JF, Wang H, He ML, Lin MC, Chen $\mathrm{Y}$ and Kung HF: Proteomic identification of microRNA-122a target proteins in hepatocellular carcinoma. Proteomics 10: 3723-3731, 2010.

11. Jin S, Ray RM and Johnson LR: TNF-alpha/cycloheximide-induced apoptosis in intestinal epithelial cells requires Rac1-regulated reactive oxygen species. Am J Physiol Gastrointest Liver Physiol 294: G928-G937, 2008.

12. Christofferson DE, Li Y and Yuan J: Control of life-or-death decisions by RIP1 kinase. Annu Rev Physiol 76: 129-150, 2014. 